\title{
Prolonged low-dose methylprednisolone treatment is highly effective in reducing duration of mechanical ventilation and mortality in patients with ARDS
}

\author{
Gianfranco Umberto Meduri ${ }^{*}$, Reed A. C. Siemieniuk ${ }^{2,3}$, Rachel A. Ness ${ }^{4}$ and Samuel J. Seyler ${ }^{5}$
}

\begin{abstract}
An updated meta-analysis incorporating nine randomized trials $(n=816)$ investigating low-to-moderate dose prolonged glucocorticoid treatment in acute respiratory distress syndrome (ARDS) show moderate-to-high quality evidence that glucocorticoid therapy is safe and reduces (i) time to endotracheal extubation, (ii) duration of hospitalization, and (iii) mortality (number to treat to save one life $=7$ ), and increases the number of days free from (i) mechanical ventilation, (ii) intensive care unit stay, and (iii) hospitalization. Recent guideline suggests administering methylprednisolone in patients with early moderate-to-severe ( $1 \mathrm{mg} / \mathrm{kg} /$ day) and late persistent $(2 \mathrm{mg} / \mathrm{kg} /$ day) ARDS (conditional recommendation based on moderate quality of evidence).
\end{abstract}

Keywords: Adult respiratory distress syndrome, Glucocorticoid treatment, Methylprednisolone, Dosage, Duration of treatment, Duration of mechanical ventilation, Tapering, Reconstituted systemic inflammation, Survival

\section{Background}

The English version of the clinical practice guidelines for the management of adult patients with ARDS (Japanese version publication July 2016) was recently published in the Journal of Intensive Care [1]. The recommendations are based on only five heterogeneous randomized controlled trials (RCTs) published before 2008. Four RCTs investigated methylprednisolone: one trial (1987) [2] administered $120 \mathrm{mg} / \mathrm{kg}$ over $24 \mathrm{~h}$ and the other (1998-2007) used $1 \mathrm{mg} / \mathrm{kg} /$ day in patients with early ARDS [3] or $2 \mathrm{mg} / \mathrm{kg} /$ day in patients with late ARDS $[4,5]$ over 4 weeks. The other trial investigated hydrocortisone and fludrocortisone over 7 days in patients with ARDS and vasopressor-dependent septic shock. The clinical practice guideline development (CPGD) committee concluded that there was no significant reduction in mortality, no increased risk for infection, and an increase in mechanical ventilation-free days (MVFD). The CPGD

\footnotetext{
* Correspondence: gmeduri@uthsc.edu

${ }^{1}$ Department of Medicine, Division of Pulmonary, Critical Care and Sleep Medicine, Memphis Veterans Affairs Medical Center (111), 1030 Jefferson Avenue, Suite room \#CW444, Memphis, TN 38104, USA

Full list of author information is available at the end of the article
}

committee concluded that the overall quality of evidence across outcomes was "moderate" to suggest (GRADE 2B) the use of methylprednisolone in a dosage of 1 to $2 \mathrm{mg} / \mathrm{kg} /$ day. In addition, the CPGD committee referenced a 2014 domestic survey reporting the common practice among Japanese doctors of administering 500-1000 mg/day (pulse dose) of methylprednisolone to patients with ARDS. We wish to present a brief update of the literature and updated guidelines that might be of practical importance to clinicians.

\section{Main body}

Recent experimental [6] and clinical research [7, 8] suggest that pulse dose methylprednisolone may not be beneficial in ARDS. In an experimental study, rats with lipopolysaccharide-induced acute lung injury were exposed to graded concentrations of methylprednisolone (3 mg, $30 \mathrm{mg}, 180 \mathrm{mg}$ ) for up to 14 days [6]. Serial BAL and lung histology demonstrated more significant improvements at $12 \mathrm{~h}$ in the higher dose group. However, by day 7 , the high-dose group had partial loss of early laboratory improvements and significantly worsen pathological scores, while the lower dose group achieved

(c) The Author(s). 2018 Open Access This article is distributed under the terms of the Creative Commons Attribution 4.0 International License (http://creativecommons.org/licenses/by/4.0/), which permits unrestricted use, distribution, and 
continued improvement in both pathological and laboratory variables [6]. Similarly, data from two recent retrospective studies suggests that pulse dose steroids may be harmful $[7,8]$. For example, in a retrospective comparison with low-dose methylprednisolone (0.5$1 \mathrm{mg} / \mathrm{kg} /$ day; $n=165$ ), high-dose methylprednisolone (1000 mg/day for 3 days followed by $2 \mathrm{mg} / \mathrm{kg} /$ day) was associated with higher 60 -day mortality and a 10-day reduction in ventilator-free days by day 28 [7].

A multi-specialty task force of international experts assembled by the Society of Critical Care Medicine and the European Society of Intensive Care Medicine recently published the updated guidelines for the diagnosis and treatment of Critical Illness Related Corticosteroid Insufficiency (CIRCI) [9]. In a separate document [10], the task force reviewed clinical and experimental evidence on the central role played by CIRCI in the pathobiology of ARDS and how increasing glucocorticoid receptor $\alpha(G R \alpha)$ activation with quantitatively adequate and prolonged glucocorticoid supplementation can reverse CIRCI and accelerate resolution of pulmonary and systemic inflammation. The impact of methylprednisolone treatment on GR $\alpha$ number and function in patients with ARDS was also reviewed $[11,12]$. For their recommendations, the task force relied mostly on a recent systematic review of RCTs investigating prolonged (7 days or greater) glucocorticoid treatment in ARDS [13]. This systematic review included a primary individual patient data meta-analysis (IPDMA) of four RCTs investigating methylprednisolone treatment $(n=322)[3-5,14]$, and an aggregate data meta-analysis incorporating four additional RCTs [15-18] investigating hydrocortisone treatment in early ARDS $(n=297)$. There were substantial differences in the treatment protocol design. Data are presented as methylprednisolone vs. hydrocortisone: an initial bolus was used in $4[3-5,14]$ vs. $2[15,17]$; duration of treatment was 24 to 32 days vs 7 days, and slow tapering of study drug was implemented in $3[3,4,14]$ vs. none.

Individual patient data meta-analyses allow for time-to-event analyses and examination of new outcomes not previously reported (e.g., MV-free days and impact of tapering). By study day 28 (Fig. 1), fewer patients in the methylprednisolone group died before extubation $(12 \%$ vs. $29 \% ; p<0.001)$ and more patients achieved extubation ( $80 \%$ vs. $50 \% ; p<0.001)$ and were discharged alive from the intensive care unit $(75 \%$ vs 49\%; $p<0.001$ ). In the methylprednisolone group, time to extubation was shorter (hazard ratio $2.59,95 \% \mathrm{CI}$ $1.95-3.43, p<0.001)$ and hospital mortality was lower ( $20 \%$ vs. $33 \%$; $p=0.006)$. The results were similar in both the aggregate (eight studies) and individual patient meta-analyses (four studies). In addition, prolonged methylprednisolone treatment was associated with (i) increased MV-free days $(13.3 \pm 11.8$ vs. $7.6 \pm 5.7 ; p<$ $0.001)$, ICU-free days ( $10.8 \pm 0.71$ vs. $6.4 \pm 0.85 ; p<$ $0.001)$, and hospital-free days to day 28 (7.0 \pm 0.57 vs. $3.8 \pm 0.68 ; p<0.001)$, and a reduction in development of shock ( $3 \%$ vs. $15 \% ; p<0.001)$ and infections $(32 \%$ vs. $41 \%$; $p=0.001)$ after study entry. In the ARDS network RCT, rapid discontinuation of study drug after extubation was associated with return to mechanical ventilation for $26 \%$ of methylprednisolone-treated patients from reconstituted systemic inflammation in the presence of adrenal suppression [19]. Despite the partial loss of early benefits associated with return to mechanical ventilation, patients randomized prior to day 14 had a $25 \%$ [ 18 of 66 (27.3\%) vs. 24 of $66(36.4 \%)$; RR 0.75 , CI 0.45 to 1.24 ] and 31\% [18 of $66(27.3 \%)$ vs. 26 of $66(39.4 \%)$; RR 0.69 , CI 0.42 to 1.13 ] relative reduction in 60-day and 180-day mortality, respectively [19].

During the consensus process, an additional RCT was published by Tongyoo et al. [20] (hydrocortisone 7 days, no bolus, no tapering) and incorporated in the final

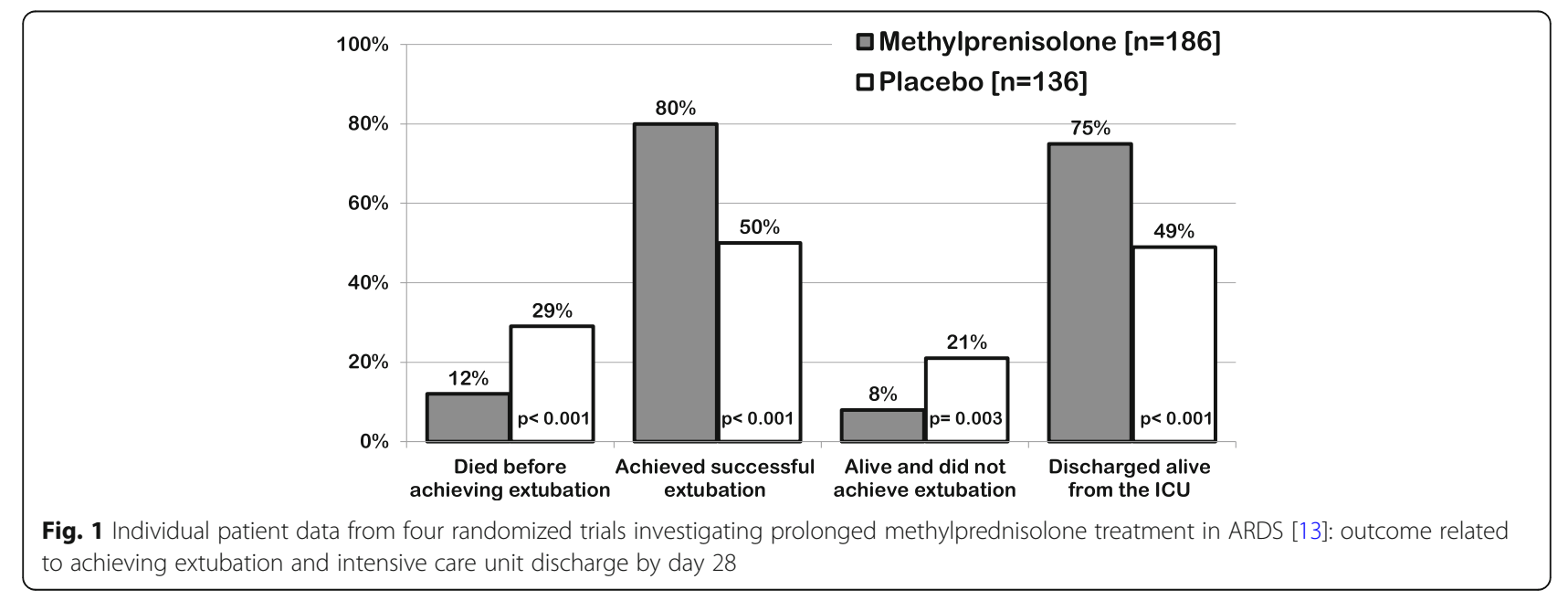


analysis of the nine trials $(n=816)$. Overall, glucocorticoid treatment was associated with reduction in MV-free days (mean difference 6.36 days, 95\% CI 2.94-9.77; $p<$ 0.001 ) and decreased hospital mortality for those randomized before day 14 of ARDS (Fig. 2, 28.2\% vs. 42.5\%, risk ratio $0.68,95 \%$ CI $0.57-0.82, I^{2} 46 \%, p<0.0001$ ). The number to treat to save one life was 7 . Except for transient hyperglycemia (mostly within the $36 \mathrm{~h}$ following an initial bolus), prolonged glucocorticoid treatment was not associated with increased risk for neuromuscular weakness [21], gastrointestinal bleeding, or nosocomial infections [9]. Importantly, the survival benefit observed during hospitalization persisted after hospital discharge with follow-up observations extending up to 1 year (limit of measurement) $[3,4,16]$.

The task force suggests administering (Table 1) methylprednisolone in patients with early (up to day 7 of onset; $\mathrm{PaO} 2 / \mathrm{FiO} 2$ of $\leq 200$ ) moderate-to-severe ARDS in a dose of $1 \mathrm{mg} / \mathrm{kg} /$ day (ideal body weight) and late (after day 6 of onset) persistent ARDS in a dose of $2 \mathrm{mg} / \mathrm{kg} /$ day followed by slow tapering over 13 days (conditional recommendation based on moderate quality of evidence). Furthermore, the task force suggested that methylprednisolone should be weaned slowly (6-14 days) and not stopped rapidly (24 days) or abruptly as deterioration may occur from the development of a reconstituted inflammatory response [9]. Since glucocorticoid treatment blunts the febrile response, infection surveillance was recommended to promptly identify and treat hospital-acquired infections [9].

Methylprednisolone may have several advantages over hydrocortisone for the treatment of ARDS. Methylprednisolone has (i) greater affinity for the glucocorticoid receptor (GR) [22], (ii) high penetration in lung tissue with longer residence time [23], and high potency for both (iii) genomic (inhibitory activity of transcription factor nuclear factor-kB) [24] and (iv) non-genomic activity [25]. Bolus administration prior to infusion achieves prompt elevation in plasma levels to assure higher GR saturation in the (i) cytoplasm and on the (ii) cell membrane for genomic and non-genomic actions, respectively. Cytoplasmic GR reach maximal saturation with approximately $100 \mathrm{mg}$ methylprednisolone equivalent [26]. Bolus-associated increase in plasma methylprednisolone level causes transient hyperglycemia that does not affect the outcome. The methylprednisolone dose of $1 \mathrm{mg} / \mathrm{kg} /$ day in early ARDS is similar to the one commonly used in other forms of interstitial lung diseases [27] and in the IPDMA was associated-in comparison to placebo-with a threefold increase in the rate extubation by day 28 (HR 3.48, 95\% CI $2.07-5.85 ; p<$ $0.0001)$ [13]. In critically ill patients, reduction in duration of mechanical ventilation is associated with a significant improvement in long-term outcomes including mortality, functional status, and quality of life $[28,29]$.

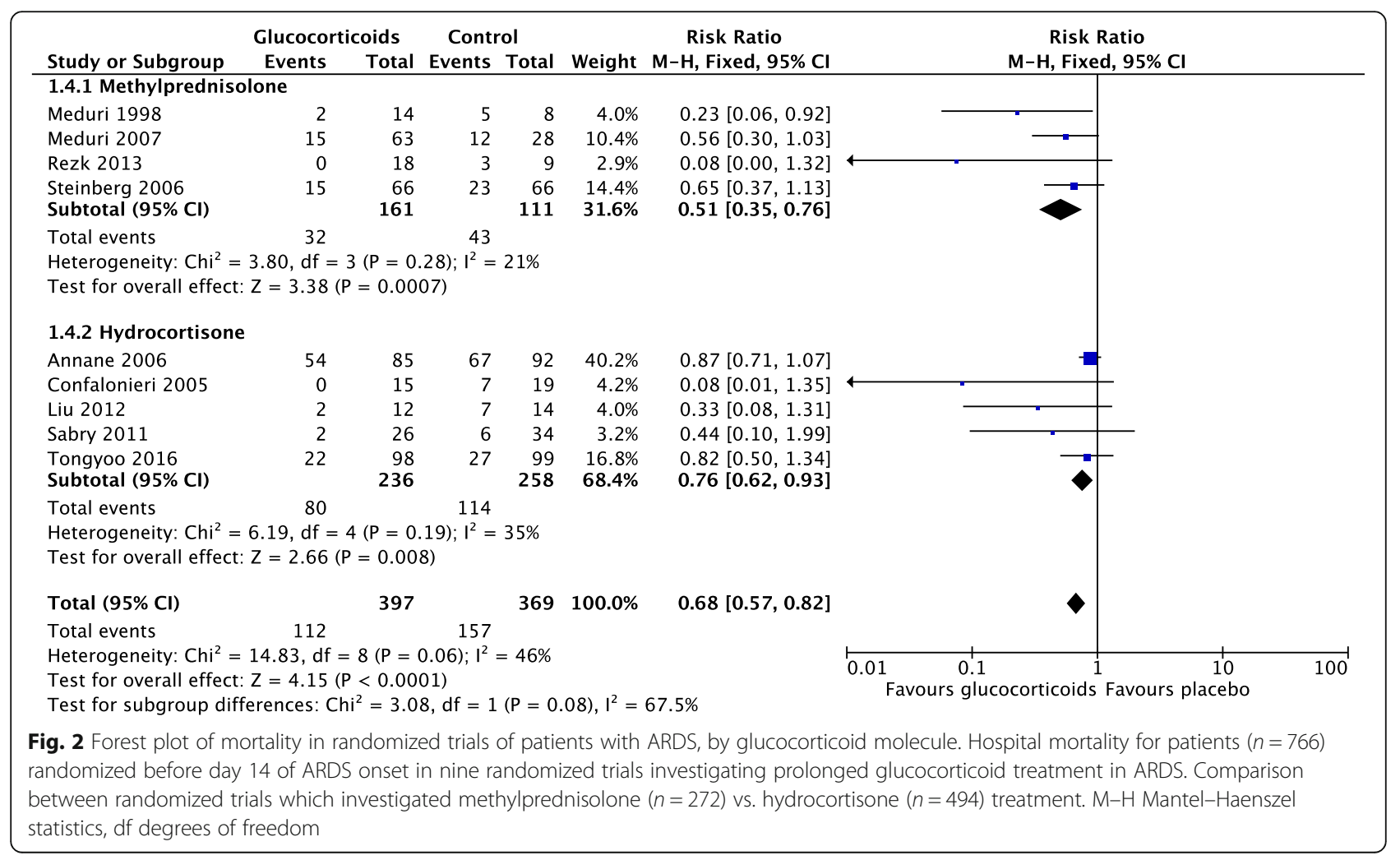


Table 1 Methylprednisolone treatment of early moderate-to-severe ARDS and late unresolving ARDS

\begin{tabular}{|c|c|c|}
\hline \multicolumn{3}{|c|}{ Early moderate-to-severe ARDS $\left(\mathrm{PaO}_{2}: \mathrm{FiO}_{2} \leq 200\right.$ on PEEP $\left.5 \mathrm{cmH}_{2} \mathrm{O}\right)$} \\
\hline Time & Intravenous administration form & Dosage \\
\hline Loading & Bolus over $30 \mathrm{~min}$ & $1 \mathrm{mg} / \mathrm{kg}$ \\
\hline Days 1 to $14^{*, t, \neq}$ & Infusion at $10 \mathrm{cc} /$ hour & $1 \mathrm{mg} / \mathrm{kg} /$ day \\
\hline Days 15 to $21^{*, \neq}$ & Infusion at $10 \mathrm{cc} /$ hour & $0.5 \mathrm{mg} / \mathrm{kg} / \mathrm{day}$ \\
\hline Days 22 to $25^{*, \neq}$ & Infusion at $10 \mathrm{cc} /$ hour & $0.25 \mathrm{mg} / \mathrm{kg} /$ day \\
\hline Days 26 to $28^{*, \neq}$ & Infusion at $10 \mathrm{cc} /$ hour & $0.125 \mathrm{mg} / \mathrm{kg} /$ day \\
\hline \multicolumn{3}{|c|}{$\begin{array}{l}\text { Unresolving ARDS = less than (a) one-point reduction in lung injury score or (b) or } 100 \text { improvement of in } \mathrm{PaO}_{2}: \mathrm{FiO}_{2} \\
\text { - By day } 7 \text { of ARDS in patients not receiving methylprednisolone for early ARDS } \\
\text { - By days 5-7 of ARDS in patients receiving methylprednisolone (above) for early ARDS }\end{array}$} \\
\hline Time & Intravenous administration form & Dosage \\
\hline Loading & Bolus over 30 min & $2 \mathrm{mg} / \mathrm{kg}$ \\
\hline Days 1 to $14^{*, t, \neq}$ & Infusion at $10 \mathrm{cc} /$ hour & $2 \mathrm{mg} / \mathrm{kg} / \mathrm{day}$ \\
\hline Days 15 to $21^{*, \neq}$ & Infusion at $10 \mathrm{cc} /$ hour & $1 \mathrm{mg} / \mathrm{kg} /$ day \\
\hline Days 22 to $25^{*, \neq}$ & Infusion at $10 \mathrm{cc} /$ hour & $0.5 \mathrm{mg} / \mathrm{kg} / \mathrm{day}$ \\
\hline Days 26 to $28^{*, \neq}$ & Infusion at $10 \mathrm{cc} /$ hour & $0.25 \mathrm{mg} / \mathrm{kg} /$ day \\
\hline Days 29 to $28^{*, \neq}$ & Bolus over $30 \mathrm{~min}$ & $0.125 \mathrm{mg} / \mathrm{kg} /$ day \\
\hline
\end{tabular}

IV = intravenous. The dosage is adjusted to ideal body weight and round up to the nearest $10 \mathrm{mg}$ (i.e., $77 \mathrm{mg}$ round up to $80 \mathrm{mg}$ ). The bolus is given over $30 \mathrm{~min}$. The infusion is obtained by adding the daily dosage to $240 \mathrm{cc}$ of normal saline and run at $10 \mathrm{cc} / \mathrm{hour}$

*Five days after the patient can ingest medications, methylprednisolone is administered per os in one single daily equivalent dose. Enteral absorption of methylprednisolone is compromised for days after extubation. Prednisone (available in 1-mg, 5-mg, 10-mg, and 20-mg strengths) can be used in place of methylprednisolone

${ }^{+}$If between days 1 to 14 the patient is extubated, the patient is advanced to day 15 of drug therapy and tapered according to schedule

${ }^{*}$ When patients leave the intensive care unit, if they are still not tolerating enteral intake for at least 5 days, they should be given the dosage specified but divided into two doses and given every $12 \mathrm{~h} \mathrm{IV}$ push until tolerating ingestion of medications by mouth

Observational studies and controlled trials have investigated the impact of early initiation of glucocorticoid treatment on preventing progression of the temporal continuum of systemic inflammation in patients with, or at risk for, ARDS. In a large retrospective observation study, among patients admitted to the ICU with sepsis, preadmission oral glucocorticoid treatment was independently associated with a lower incidence of ARDS (35\% vs. $42 \% ; p=0.008$ ) [30]. Two prospective controlled studies found that the intra-operative intravenous administration of methylprednisolone (125 or $250 \mathrm{mg}$ ) reduced the incidence of post-surgical ALI ARDS in patients undergoing pneumonectomy $(N=72 ; 0 \%$ vs. $13.5 \%, p<0.05)[31]$ and esophagectomy $(N=234 ; 1.3 \%$ vs. 9.3\%; $p=0.04)$ [32]. In aggregate data from four RCTs in patients $(n=945)$ hospitalized with community-acquired pneumonia, early prolonged glucocorticoid treatment prevented progression to ARDS ( $N=945 ; 0.4 \%$ vs. $3.0 \%$; RR $0.24,95 \%$ CI $0.24,0.10-0.56$ ) [33]. In patients with early ARDS, prolonged methylprednisolone treatment prevented progression to respiratory failure requiring mechanical ventilation $(42 \%$ vs. $100 \% ; p=0.02)$ [34] or progression to unresolving ARDS ( $8 \%$ vs. $36 \% ; p=$ 0.002) [3].

Finally, the ARDS network RCT "Efficacy of Corticosteroids as Rescue Therapy for the Late Phase of
Acute Respiratory Distress Syndrome (LaSRS)" [5] is frequently quoted-in isolation of the updated literature-to negate a therapeutic benefit for prolonged glucocorticoid treatment in ARDS [35]. Contrary to the misinformation associated with this publication, a recent re-analysis of the data demonstrates that methylprednisolone treatment was safe and highly effective in achieving disease resolution with sizable and significant improvements in all pre-specified secondary outcomes [19].

\section{Conclusions}

In summary, there is moderate-to-high quality evidence that prolonged glucocorticoid therapy is safe and reduces (i) time to endotracheal extubation, (ii) duration of hospitalization, and (iii) mortality (number to treat to save one life $=7$ ), and increases the number of days free from (i) mechanical ventilation, (ii) intensive care unit stay, and (iii) hospitalization. The mortality benefits-in comparison to placebo-persist after hospitalization. The adverse effects from glucocorticoids appear to be minimal and not important to patients (e.g., hyperglycemia). We believe that based on this evidence, all or almost all fully informed patients with ARDS would choose to use glucocorticoid therapy following the protocol outlined in Table 1. 


\section{Response to Meduri et al.: "Prolonged low-dose methylprednisolone treatment is highly effective in reducing duration of mechanical ventilation and mortality in patients with ARDS"}

Satoru Hashimoto ${ }^{6}$, Masamitsu Sanui ${ }^{7}$ and Moritoki Egi ${ }^{8}$

${ }^{1}$ Department of Anesthesiology and Intensive Care, Kyoto Prefectural University of Medicine, Kyoto, Japan

${ }^{2}$ Department of Anesthesiology and Critical Care Medicine, Jichi Medical University Saitama Medical Center, Sai-

tama, Japan

${ }^{3}$ Department of anesthesiology, Kobe University Hospital, Kobe, Japan

We read the letter to the editors from Dr. Meduri et al. with great interest. First of all, we congratulate their effort to elucidate the effects of prolonged treatment with low-dose methylprednisolone treatment for patients with ARDS. Guideline by Annane et al. clearly showed the beneficial effects of corticosteroids on ARDS [9]. Whereas our analyses for the guideline did not show any statistically significant reduction in mortality, a lower risk ratio in patients with glucocorticoids was suggested (0.83 [95\% confidential interval 0.65, 1.07]) [1]. At least, the use of glucocorticoids may have less chance to increase the mortality risk, while the use of glucocorticoids was significantly associated with the longer ventilator-free days (mean difference [CI] 5.67 [3.49-7.68] days). Based on these results, our guideline suggested the administration of corticosteroids (equivalent to methylprednisolone $1-2 \mathrm{mg} / \mathrm{kg} /$ day) to adult patients with ARDS (GRADE 2B, "weak recommendation"/quality of evidence "moderate").

As suggested by Meduri et al., it might be better not to include the study by Bernard et al., since the doses and duration of methylprednisolone were exceptional (i.e., large doses of methylprednisolone on a single day) [2]. Of note, however, the effects of glucocorticoids on mortality and infection rates did not reach a significant difference even after excluding this study (mortality: $p=0.14$, risk ratio $=0.76[95 \%$ confidential interval $0.52,1.10]$; infection rate: $p=0.08$, risk ratio $=0.80[95 \%$ confidential interval $0.62,1.03]$ ). Also, there are four studies included in the meta-analysis by Meduri et al., but not included in our analysis [13]. Two of the four studies examined patients with community-acquired pneumonia $[15,17]$ : one was written in Chinese (only English or Japanese literature included in our meta-analysis) [18] and the last one was not included in our search engines (i.e., MEDLINE, EMBASE, and Cochrane CENTRAL) [14]. One more study by Tongyoo cited in this study showed significant improvement in pulmonary physiology, but the study itself did not show significant survival benefit [20]. Despite an exclusion of these five studies, the results of our analysis are in the same line of their metaanalysis. And we agree with Dr. Meduri's suggestion that methylprednisolone may have several advantages over hydrocortisone for the treatment of ARDS.

The very latest multicenter randomized controlled trial by Venkatesh et al. (ADRENAL trial) evaluated the effectiveness of low-dose hydrocortisone (at a dose of $200 \mathrm{mg}$ per day) during the initial 7 days for 3658 mechanically ventilated patients with septic shock [36]. In this trial, the use of hydrocortisone did not decrease the 90-day mortality $(p=0.50)$, while patients with hydrocortisone had faster resolutions of shock than those with placebo (hazard ratio, $1.32 ; p<0.001$ ). However, there were no significant differences in the number of days alive and free from mechanical ventilation. Based on the results from ADRENAL trial and moderate quality of evidences noted in the meta-analyses for ARDS, more solid evidences are needed to recommend the routine use of glucocorticoids for patients with ARDS.

As Meduri et al. pointed out, large doses of methylprednisolone were occasionally administered for patients with ARDS or interstitial pneumonia in Japan. A survey for 296 hospitals in Japan revealed that so-called steroid pulse therapy (1000 $\mathrm{mg}$ of methylprednisolone for 3 days) was routinely used for patients with ARDS in approximately one third of the surveyed hospitals [37]. These unproven therapies should also be evaluated in future trials.

\section{Abbreviations \\ ARDS: Acute respiratory distress syndrome; CIRCI: Critical IIIness Related Corticosteroid Insufficiency; CPGD: Clinical practice guideline development; IPDMA: Individual patient data meta-analysis; IV: Intravenous; RCT: Randomized controlled trial}

\section{Funding \\ This material is the result of work supported with the resources and use of facilities at the Memphis VA Medical Center. The contents of this review do not represent the views of the US Department of Veterans Affairs or the US Government.}

\section{Authors' contributions}

GUM developed the original draft, and all authors (GUM, RACS, RAN, and SJS) contributed equally to the final version. All authors reviewed and approved the final report.

Ethics approval and consent to participate Not applicable 


\section{Consent for publication}

Not applicable

\section{Competing interests}

The authors declare that they have no competing interests.

\section{Publisher's Note}

Springer Nature remains neutral with regard to jurisdictional claims in published maps and institutional affiliations.

\section{Author details}

'Department of Medicine, Division of Pulmonary, Critical Care and Sleep Medicine, Memphis Veterans Affairs Medical Center (111), 1030 Jefferson Avenue, Suite room \#CW444, Memphis, TN 38104, USA. ${ }^{2}$ Department of Health Research Methods, Evidence, and Impact, McMaster University, Hamilton, Ontario, Canada. ${ }^{3}$ Department of Medicine, University of Toronto, Toronto, Ontario, Canada. ${ }^{4}$ Department of Pharmacy, Memphis Veterans Affairs Medical Center, Memphis, TN, USA. ${ }^{5}$ Department of Medicine and Pediatrics, University of Tennessee Health Science Center, Memphis, TN, USA.

Received: 4 May 2018 Accepted: 7 August 2018

\section{Published online: 24 August 2018}

\section{References}

1. Hashimoto S, Sanui M, Egi M, Ohshimo S, Shiotsuka J, Seo R, Tanaka R, Tanaka $Y$, Norisue $Y$, Hayashi $Y$, et al. The clinical practice guideline for the management of ARDS in Japan. J Intensive Care. 2017;5(1):50.

2. Bernard GR, Luce JM, Sprung CL, Rinaldo JE, Tate RM, Sibbald WJ, Kariman K, Higgins S, Bradley R, Metz CA, et al. High-dose corticosteroids in patients with the adult respiratory distress syndrome. N Engl J Med. 1987;317(25): 1565-70.

3. Meduri GU, Golden E, Freire AX, Taylor E, Zaman M, Carson SJ, Gibson M, Umberger R. Methylprednisolone infusion in early severe ARDS: results of a randomized controlled trial. Chest. 2007;131(4):954-63.

4. Meduri GU, Headley AS, Golden E, Carson SJ, Umberger RA, Kelso T, Tolley EA. Effect of prolonged methylprednisolone therapy in unresolving acute respiratory distress syndrome: a randomized controlled trial. JAMA. 1998; 280(2):159-65

5. Steinberg KP, Hudson LD, Goodman RB, Hough CL, Lanken PN, Hyzy R, Thompson BT, Ancukiewicz M. Efficacy and safety of corticosteroids for persistent acute respiratory distress syndrome. N Engl J Med. 2006;354(16): 1671-84.

6. Teng D, Pang QF, Yan WJ, Zhao Xin W, Xu CY. The harmful effect of prolonged high-dose methylprednisolone in acute lung injury. Int Immunopharmacol. 2013;15(2):223-6.

7. Takaki M, Ichikado K, Kawamura K, Gushima Y, Suga M. The negative effect of initial high-dose methylprednisolone and tapering regimen for acute respiratory distress syndrome: a retrospective propensity matched cohort study. Crit Care. 2017;21(1):135.

8. Kido T, Muramatsu K, Asakawa T, Otsubo H, Ogoshi T, Oda K, Kubo T, Fujino Y, Matsuda S, Mayumi T. The relationship between high-dose corticosteroid treatment and mortality in acute respiratory distress syndrome: a retrospective and observational study using a nationwide administrative database in Japan. BMC Pulm Med. 2018;18(1):28.

9. Annane D, Pastores S, Rochwerg B, Arlt W, Balk R, Beishuizen A, Briegel J, Carcillo J, Christ-Crain M, Cooper M. Guidelines for the diagnosis and management of Critical IIIness-Related Corticosteroid Insufficiency (CIRCI) in critically ill patients (part I): Society of Critical Care Medicine (SCCM) and European Society of Intensive Care Medicine (ESICM) 2017. Crit Care Med. 2017:45(12):2078-88

10. Annane D, Pastores S, Arlt W, Balk R, Beishuizen A, Briegel J, Carcillo J, Christ-Crain M, Cooper M, Marik P. Critical Illness-Related Corticosteroid Insufficiency (CIRCI): a narrative review from a Multispecialty Task Force of the Society of Critical Care Medicine (SCCM) and the European Society of Intensive Care Medicine (ESICM). Crit Care Med. 2017;45(12):2089-99.

11. Annane D, Pastores SM, Arlt W, Balk RA, Beishuizen A, Briegel J, Carcillo J, Christ-Crain M, Cooper MS, Marik PE, et al. Critical illness-related corticosteroid insufficiency (CIRCI): a narrative review from a Multispecialty Task Force of the Society of Critical Care Medicine (SCCM) and the European Society of Intensive Care Medicine (ESICM). Intensive Care Med. 2017;43(12):1781-92
12. Meduri GU, Tolley EA, Chrousos GP, Stentz F. Prolonged methylprednisolone treatment suppresses systemic inflammation in patients with unresolving acute respiratory distress syndrome. Evidence for inadequate endogenous glucocorticoid secretion and inflammation-induced immune cell resistance to glucocorticoids. Am J Respir Crit Care Med. 2002;165(7):983-91.

13. Meduri GU, Bridges L, Shih MC, Marik PE, Siemieniuk RAC, Kocak M. Prolonged glucocorticoid treatment is associated with improved ARDS outcomes: analysis of individual patients' data from four randomized trials and trial-level meta-analysis of the updated literature. Intensive Care Med. 2016;42(5):829-40.

14. Rezk N, Ibrahim A. Effects of methylprednisolone in early ARDS. Egypt J Chest Dis Tuberc. 2013;62(1):167-72.

15. Confalonieri M, Urbino R, Potena A, Piattella M, Parigi P, Puccio G, Della Porta R, Giorgio C, Blasi F, Umberger R, et al. Hydrocortisone infusion for severe community-acquired pneumonia: a preliminary randomized study. Am J Respir Crit Care Med. 2005;171(3):242-8.

16. Annane D, Sebille V, Bellissant E, Ger-Inf-05 Study G. Effect of low doses of corticosteroids in septic shock patients with or without early acute respiratory distress syndrome. Crit Care Med. 2006;34(1):22-30.

17. Sabry NA, Omar EE-D. Corticosteroids and ICU course of community acquired pneumonia in Egyptian settings. Pharmacol Pharm. 2011;2:73-81.

18. Liu L, Li J, Huang YZ, Liu SQ, Yang CS, Guo FM, Qiu HB, Yang Y. The effect of stress dose glucocorticoid on patients with acute respiratory distress syndrome combined with critical illness-related corticosteroid insufficiency. Zhonghua Nei Ke Za Zhi. 2012;51(8):599-603.

19. Meduri GU, Bridges L, Siemieniuk RAC, Kocak M. An exploratory reanalysis of the randomized trial on efficacy of corticosteroids as rescue therapy for the late phase of acute respiratory distress syndrome. Crit Care Med. 2018; https://doi.org/10.1097/CCM.0000000000003021). Published ahead of print

20. Tongyoo S, Permpikul C, Mongkolpun W, Vattanavanit V, Udompanturak S, Kocak M, Meduri GU. Hydrocortisone treatment in early sepsis-associated acute respiratory distress syndrome: results of a randomized controlled trial. Crit Care. 2016;20(1):329.

21. Meduri GU, Schwingshackl A, Hermans G. Prolonged glucocorticoid treatment in ARDS: impact on intensive care unit-acquired weakness. Front Pediatr. 2016:4:69.

22. Mager DE, Moledina N, Jusko WJ. Relative immunosuppressive potency of therapeutic corticosteroids measured by whole blood lymphocyte proliferation. J Pharm Sci. 2003;92(7):1521-5.

23. Greos LS, Vichyanond P, Bloedow DC, Irvin CG, Larsen GL, Szefler SJ, Hill MR. Methylprednisolone achieves greater concentrations in the lung than prednisolone. A pharmacokinetic analysis. Am Rev Respir Dis. 1991;144(3 Pt 1):586-92.

24. Li SMG, Miller DD, Yates CR. Evaluation of AP-1 and NF-kB inhibitory potency for oral glucocorticoids. PharmSci. 2003;5(S1):Abstract R6173.

25. Croxtall JD, Van Hal PTW, Choudhury Q, Gilroy DW, Flower RJ. Different glucocorticoids vary in their genomic and non-genomic mechanism of action in A549 cells. Br J Pharmacol. 2002;135(2):511-9.

26. Buttgereit F, da Silva JA, Boers M, Burmester GR, Cutolo M, Jacobs J, Kirwan J, Kohler L, Van Riel P, Vischer T, et al. Standardised nomenclature for glucocorticoid dosages and glucocorticoid treatment regimens: current questions and tentative answers in rheumatology. Ann Rheum Dis. 2002;61(8): 718-22.

27. Jantz MA, Sahn SA. Corticosteroids in acute respiratory failure. Am J Respir Crit Care Med. 1999;160(4):1079-100.

28. Wilson ME, Barwise A, Heise KJ, Loftsgard TO, Dziadzko M, Cheville A, Majzoub A, Novotny PJ, Gajic O, Biehl M. Long-term return to functional baseline after mechanical ventilation in the ICU. Crit Care Med. 2018;46(4): 562-9.

29. Combes A, Costa MA, Trouillet JL, Baudot J, Mokhtari M, Gibert C, Chastre J. Morbidity, mortality, and quality-of-life outcomes of patients requiring $>=$ 14 days of mechanical ventilation. Crit Care Med. 2003;31(5):1373-81.

30. McKown AC, McGuinn EM, Ware LB, Wang L, Janz DR, Rice DA, Semler MW. Pre-admission oral corticosteroids are associated with reduced risk of acute respiratory distress syndrome in critically III adults with sepsis. Crit Care Med. 2017:45:774.

31. Cerfolio RJ, Bryant AS, Thurber JS, Bass CS, Lell WA, Bartolucci AA. Intraoperative solumedrol helps prevent postpneumonectomy pulmonary edema. Ann Thorac Surg. 2003;76(4):1029-33. discussion 1033-1025

32. Park SY, Lee HS, Jang HJ, Joo J, Zo Jl. Efficacy of intraoperative, single-bolus corticosteroid administration to prevent postoperative acute respiratory 
failure after oesophageal cancer surgery. Interact Cardiovasc Thorac Surg. 2012;15(4):639-43.

33. Siemieniuk RA, Meade MO, Alonso-Coello P, Briel M, Evaniew N, Prasad M, Alexander PE, Fei Y, Vandvik PO, Loeb M, et al. Corticosteroid therapy for patients hospitalized with community-acquired pneumonia: a systematic review and meta-analysis. Ann Intern Med. 2015;163(7):519-28.

34. Lee HS, Lee JM, Kim MS, Kim HY, Hwangbo B, Zo Jl. Low-dose steroid therapy at an early phase of postoperative acute respiratory distress syndrome. Ann Thorac Surg. 2005;79(2):405-10.

35. Thompson BT, Chambers RC, Liu KD. Acute respiratory distress syndrome. N Engl J Med. 2017;377(6):562-72.

36. Venkatesh B, Finfer S, Cohen J, Rajbhandari D, Arabi Y, Bellomo R, et al. Adjunctive glucocorticoid therapy in patients with septic shock. N Engl J Med. 2018;378(9):797-808.

37. Tasaka S, Tatsumi K, Assembly of Pulmonary C, Lung Injury tIRS. Clinical practice of acute respiratory distress syndrome in Japan: a nationwide survey and scientific evidences. Respir Investig. 2017;55(4):257-263

Ready to submit your research? Choose BMC and benefit from:

- fast, convenient online submission

- thorough peer review by experienced researchers in your field

- rapid publication on acceptance

- support for research data, including large and complex data types

- gold Open Access which fosters wider collaboration and increased citations

- maximum visibility for your research: over $100 \mathrm{M}$ website views per year

At $\mathrm{BMC}$, research is always in progress.

Learn more biomedcentral.com/submissions 